\title{
On the Release of Players to National Teams
}

\author{
Oliver Guertler ${ }^{\dagger}$, Markus Lang ${ }^{\dagger \dagger}$, and Tim Pawlowski ${ }^{\dagger \dagger}$
}

November 2011

\begin{abstract}
The release of players from a club to the national team often leads to a conflict concerning the duration of the players' stay with the national team. Based on a theoretical bargaining model, we examine whether intervention in this conflict by a governing body is desirable. We show that bargaining between the club and the national team yields a socially inefficient outcome if financial compensation is either prohibited or limited. If, however, the national team is allowed to pay unlimited financial compensation to the club, it is not necessary to intervene in the negotiations because the bargaining outcome will be socially optimal.
\end{abstract}

JEL Classification Codes: C78, L83

Keywords: National team, release of players, compensation payment, bargaining, team sports

*We would like to thank Arne Feddersen, Stefan Késenne, Gunther König, Thomas Peeters and the participants in the NAASE Sports Economics Sessions at the 85th WEAI Conference in Portland as well as the 14th Annual Meeting of the German Association of Sport Economics and Sport Management (AK Sportökonomie) in Saarbrücken for their valuable comments and suggestions on an earlier version of this paper. Markus Lang gratefully acknowledges the financial support provided by the Ecoscientia Foundation and the Foundation for the Advancement of Young Scientists (FAN) of the Zürcher Universitätsverein (ZUNIV).

${ }^{\dagger}$ University of Cologne, Department of Economics, Albertus-Magnus Platz, D-50923 Cologne, Germany, Tel.: +49 221 4701450, Fax: +49 221 4701816, E-mail: oliver.guertler@unikoeln.de.

$\dagger^{\dagger}$ Institute for Strategy and Business Economics, University of Zurich, Plattenstrasse 14 CH-8032 Zurich, Switzerland, Phone: +41 (0) 4463453 11, Fax: +41 (0) 4463453 01, markus.lang@isu.uzh.ch

${ }^{\dagger \dagger \dagger}$ Corresponding author: German Sport University Cologne, Department of Sport Economics and Sport Management, Am Sportpark Müngersdorf 6, D-50933 Cologne, Germany, Tel.: +49221 4982 6098, Fax +49 2214982 8141, E-mail: pawlowski@ dshs-koeln.de. 


\section{Introduction}

In all team sports, players with outstanding performance play not only for their clubs but also for the national teams of their respective countries. As players are contracted by their clubs, in general it can be argued that the national federations borrow the clubs' key resource (i.e., the players) to produce their own output (i.e., international fixtures). Until now, paying a fee for such kinds of rental has not been common in professional team sports. However, recently, the International Federation of Association Football (FIFA), the Union of European Football Associations (UEFA) and some national federations have agreed upon financial payments to the clubs and compensation for their insurance premiums for releasing a player to a national team. For example, a total amount of more than 170 million euros was/will be provided by FIFA and UEFA for the 2008, 2010, 2012 and 2014 soccer tournaments. ${ }^{1}$

However, especially managers of large-market clubs complain about the release of players to the national teams as well as the magnitude of the corresponding compensation payments due to two reasons. First, large and financially successful clubs are "global brands," the appeal of which reaches far beyond national borders in a commercially significant way. Therefore, the national team is only of minor importance to the market in which those large clubs operate. Second, there is an increased risk of injuries due to the players being overworked.

So far, in spite of the topicality and relevance of this issue, the sports economics literature has neglected to analyze the conflict between clubs and national teams

\footnotetext{
${ }^{1}$ In detail, UEFA paid 4'200 euros per player and day for the clubs releasing a player to the European Championship in Austria and Switzerland 2008, amounting up to 43.3 million euros. These compensation payments will be increased to 5'000 euros per player and day in 2012 when the European Championship is going to take place in Poland and Ukraine, summing up to around 55 million euros. In addition, FIFA paid 1'000 euros per player and day for the clubs releasing a player to the World Cup in South Africa 2010, adding up to 27.5 million euros. These compensation payments will be increased to 1'700 euros per player and day in 2014 when the World Cup is going to take place in Brazil, amounting to around 48 million euros (see UEFA, 2008; Sport.t-online, 2008). Furthermore, the German Football Federation (DFB) pays around 45'000 euros per player to the clubs that release a player to friendly matches, totaling around 600 '000 euros per year, and covers for all matches of the national team the insurance premium for the entire period (DFB, 2011). Note, however, that the situation on the level of the national federations in Europe is still heterogeneous. To the best of our knowledge, e.g., the Spanish Football Federation (RFRF) also covers the insurance premiums, while the English Football Federation (FA) does not cover any costs at the moment.
} 
regarding the release of players. ${ }^{2}$ Previous research into the application of economic concepts to sporting activities focuses primarily on the analysis of whether it is necessary for sports governing bodies to intervene in the labor market and/or provide cross subsidies between clubs regarding the distribution of revenues. Competitive imbalance, resulting in uninteresting games and skyrocketing player salaries, plays a dominant role in the list of dangers cited in all the attempts to regulate the labor markets of professional team sports. ${ }^{3}$ Throughout their history, professional team sports have employed a wide array of regulations to safeguard against these dangers. Reserve clauses limiting the free agency of players, the reverse-order rookie draft and revenue-sharing arrangements are well-known examples in this context. ${ }^{4}$ Salary caps represent another prominent policy tool used in the struggle for cost control and the promotion of competitive balance. ${ }^{5}$

In this paper, we aim to understand the institutional arrangements regarding the release of players to the national team. Moreover, based on a theoretical bargaining model, we examine the circumstances under which intervention in the conflict by a sports association is desirable. Our model shows that the parties will end up with a socially inefficient outcome if financial compensation is prohibited. If, however, the national team is allowed to pay financial compensation to the clubs, then, in general, it is not necessary to intervene in the negotiations because the parties will achieve the socially optimal outcome. Under the assumption that the national team is financially constrained such that it is not able to pay the amount demanded by the club, the bargaining outcome will again be socially inefficient. Nevertheless, a governing body such as UEFA or FIFA always has an instrument with which to implement the socially optimal outcome by setting a lower bound to the duration of the players' stay with the national team.

The remainder of the paper is structured as follows. In Section 2, we provide

\footnotetext{
${ }^{2}$ Benz \& Franck (2005) consider a related conflict between a soccer club and a player. They show that it can be solved by contractual means.

${ }^{3}$ For studies about competitive balance in sports leagues, see, e.g., Szymanski (2001, 2003), Fort \& Lee (2007), Fort \& Quirk (2011), Gürtler (2007), Pawlowski et al. (2010) and Pawlowski \& Anders (2011).

${ }^{4}$ For contributions that analyze the effect of revenue-sharing arrangements, see, e.g., Fort \& Quirk (1995), Vrooman (2007, 2008), Szymanski \& Késenne (2004), Kräkel (2007), Dietl, Lang \& Werner (2009) and Dietl, Lang \& Rathke (2011).

${ }^{5}$ See, e.g., Késenne (2000, 2003, 2007), Dietl, Lang \& Rathke (2009) and Dietl, Franck, Lang \& Rathke (2011) for theoretical analyses of salary caps.
} 
a detailed description of the trade-off within and between clubs and federations. In Section 3, we introduce the analytical framework with its main assumptions. We analyze the bargaining process between clubs and federations in Section 4. In Section 5, we summarize the main results and discuss further research directions.

\section{The Trade-off within and between Clubs and Federations}

According to Baumeister et al. (2004), clubs benefit from players playing in the national team, because spectators favor teams with a high number of national players. For example, for the 2009/10 season, Figure 1 shows that there are significant correlations between the average match day attendance per club and the number of players per club playing in a national team for the "Big Four" European football leagues. ${ }^{6}$

Furthermore, players who are members of the national team might become icons, especially for younger fans. As a result, clubs can benefit through the positive image effects of a successful national team (see also Tripcke, 2001) and have improved possibilities concerning the commercialization of these players (e.g., increasing the sales of merchandise). ${ }^{7}$ In addition, a player's market value can increase with good performances in the national team. These examples indicate that clubs might have a general interest in the existence of national teams and the release of players to national teams.

Besides these positive spillover effects, some risks and disadvantages exist for the clubs when players are released to the national team. For instance, as observed by Lucifora \& Simmons (2003), national players on average earn four times as much as other football players. From an economic perspective, such salary differentials

\footnotetext{
${ }^{6}$ The "Big Four" leagues in Europe are the English Premier League, the Spanish Primera Division, the Italian Serie A and the German Bundesliga. Note that we have not found any significant correlation in the French Ligue 1. Furthermore, based on this simple test, we only provide information on correlation and not causality. It might well be the case that higher attendance figures, which lead to larger revenue streams, improve the club's possibilities for contracting national players.

${ }^{7}$ While this impact is expected to be comparatively small in professional soccer as many clubs themselves are powerful "global brands" (e.g., FC Barcelona, Manchester United) it might be of importance in other sports; e.g., in rugby with the All Blacks (New Zealand) or the Springbocks (South African).
} 

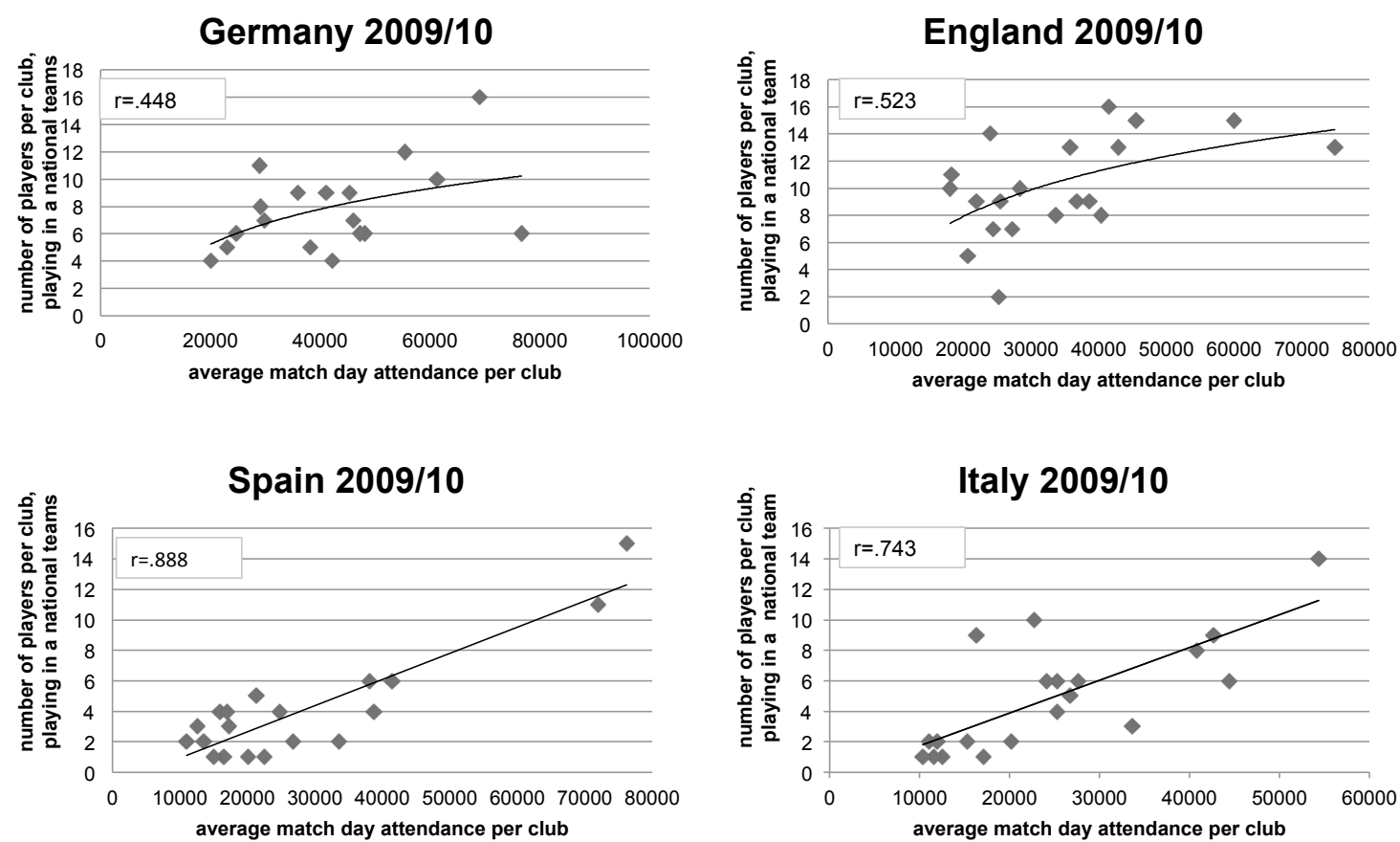

Figure 1: National players and match day attendance

might be explained by the different degrees of human capital for national and nonnational players (Hübl \& Swieter, 2002). Therefore, clubs might have to raise players' salaries after they have been capped for the national team for the first time. Recent data provide anecdotal evidence for this claim. While official data on players' salaries are hard to find in Europe, the Major League Soccer Players Union (MLSPU) publishes the salaries of players in Major League Soccer (MLS) from 2007 to 2010. Comparing the development of salaries, it appears that salaries increase by around $45 \%$ on average the year after the player has been nominated for his national team for the first time.

In addition, there is an increased risk of injuries due to the overworking of players (Ekstrand et al., 2004; Hägglund et al., 2009). According to Waldén et al. (2007), around $11 \%$ of all 672 players of countries that qualified for the men's European Championship 2004, the women's European Championship 2005 and the men's Under-19 European Championship were injured during the competitions. ${ }^{8}$ Hence, when players are injured while they are away with the national team, it often prevents them from playing for their clubs for significant periods afterwards.

\footnotetext{
${ }^{8}$ In detail, these injuries resulted in a total of 224 days of absence during the tournament and another 828 days spent on rehabilitation after the championships. This means an absence from football of 13 days on average and 46 days per severe injury, i.e., an injury causing more than 28 days' absence from training and match play (20\% of the total injuries).
} 
Further problems occur if clubs' and national teams' fixtures are scheduled at the same time. For instance, the matches of the youth teams (e.g., the FIFA Under-20 World Cup 2009 in Egypt, the Olympic competitions in which national teams with players under 21 are participating) are scheduled independently from the matches of the seniors (Tripcke, 2001). However, this conflict might also occur for senior players. ${ }^{9}$ As a result, the club officials are faced with the trade-off of whether or not to let the players play for their country if tournaments are scheduled simultaneously with the match days of the clubs. Finally, players who are released to the national team cannot train with their clubs. Having only partial squads available for training can adversely affect the subsequent performance of the teams.

Similarly, a trade-off also occurs for the corresponding national federations. Having a (successful) national team generates direct cash flows for the federations. For instance, Oliver Bierhoff, manager of the German national team, mentioned that the German Football Federation (DFB) receives on average 5 to 6 million euros for an international match (Gartenschläger, 2010). At the same time, the national federations also care about the quality of club football because some income resources of the federations are closely related to the quality of club football. Take Germany as an example, where the DFB markets the national league cup, which generates a cash flow of around 50 million euros per year (Schmidt, 2010).

Summing up, the release of players to the national team generates a trade-off between positive and negative effects for both clubs and federations. The size of these effects depends on the total duration of a player being with the national team or with the club, i.e., the frequency of releasing a player multiplied by the period of time per release. This means that clubs as well as federations are faced with a classical economic problem of how to allocate scarce resources efficiently, i.e., the length of time for which they forgo the player's talent. As a result of the different trade-offs for the federations and clubs, one can expect that a conflict emerges between both parties regarding the optimal duration of the players' stay with the national team. In general, federations might prefer a longer stay of the players with

\footnotetext{
${ }^{9}$ For instance, in June 2007, Robinho (Brazil) was expected to play with the Selecao at the Copa América, whereas Diarra should play with Mali at the qualification for the Africa Cup. Since Real Madrid had to play the final league match against Mallorca during the same period, FIFA president Blatter decided that (exceptionally) the club's games took precedence over the international matches.
} 
the national team than the clubs.

\section{Analytical Framework}

Consider a representative club $C$ and a national team $T .{ }^{10}$ Denote by $d \geq 0$ the duration of the stay of the club's players with the national team. We assume that a maximum duration $d_{\max }>0$ exists for which players are able to stay with the national team such that $d \in\left[0, d_{\max }\right]=: D .{ }^{11}$ Both the club's utility and the national team's utility depend on $d$ and are given by $u_{C}(d): D \rightarrow R$ and $u_{T}(d): D \rightarrow R$. We assume that $u_{C}(d)$ and $u_{T}(d)$ are both $C^{2}$ functions that satisfy the following assumptions:

A1. $u_{C}^{\prime}(d)<u_{T}^{\prime}(d)$ for all $d \in D$,

A2. $u_{C}^{\prime}(0)>0, u_{T}^{\prime}\left(d_{\max }\right)<0$,

A3. $u_{C}^{\prime \prime}(d)<0, u_{T}^{\prime \prime}(d)<0$.

A1-A3 reflect the ideas expressed in the previous section. $C$ and $T$ agree that it is good to have the players to spend some time with the national team, but also that the players should not be away from the club for too long. According to A1, the national team benefits marginally more than the club from the players staying with the national team for an additional spell. A combination of A1 and A2 implies that (interior) optimal durations for the players to stay with the national team exist for both the club and the national team. We denote by $d_{C} \equiv \arg \max _{d \in D} u_{C}(d) \in D$ and $d_{T} \equiv \arg \max _{d \in D} u_{T}(d)$ the optimal durations from the perspective of the clubs and the national team, respectively. A3 implies decreasing returns to an increase in the duration $d$ of the players' stay at both the club and the national team.

From A1-A3, we derive the following lemma:

Lemma 1 The club and the national team disagree about the optimal duration for which the players should stay with the national team.

Proof. The proof is straightforward by noting that $d_{C}<d_{T}$.

\footnotetext{
${ }^{10}$ Note that the club can also be represented by a club association and the national team by its national federation.

${ }^{11}$ This is just a technical assumption to ensure that $D$ is a compact set. It is obviously fulfilled in real-world settings because players cannot stay with the national team forever.
} 
Lemma 1 formalizes the observations in the previous section. Because the marginal gain in utility of a higher $d$ is smaller for the club than for the national team, $C$ prefers a shorter stay of the players with the national team than $T$ would like to see, i.e., $d_{C}<d_{T}$.

In what follows, we analyze the possible ways in which $d$ could be determined in practice. To be able to evaluate these solutions from a social point of view, we define the total utility as $U(d):=u_{C}(d)+u_{T}(d)$ and determine the socially optimal solution in the following proposition:

Proposition 1 A socially optimal duration $d_{f b}$ of the players' stay with the national team exists and is unique in $D$.

Proof. See Appendix A.1.

The proposition shows that a socially optimal duration of the players' stay with the national team exists, denoted by $d_{f b} \in D$, which is implicitly defined by the first-order condition

$$
U^{\prime}\left(d_{f b}\right)=u_{C}^{\prime}\left(d_{f b}\right)+u_{T}^{\prime}\left(d_{f b}\right)=0 .
$$

It should be noted that the socially optimal duration $d_{f b}$ is an interior solution in the interval $D$ of feasible durations because $d_{T}<d_{\max }$.

Figure 2 depicts the utilities $u_{C}$ and $u_{T}$ of the club and the national team, respectively, as a function of the duration $d$ of the players' stay with the national team. The figure reflects assumptions A1-A3. Note that the socially optimal duration $d_{f b}$ is within the interval $\left[d_{C}, d_{T}\right] .{ }^{12}$ In Figure 2 , the utility of the national team increases above that of the club. However, this is not necessarily true because A1-A3 do not impose this.

\section{Results}

To examine whether it is necessary to intervene in the negotiations between a club and a national team regarding the release of players, our analysis is structured as follows. First, we analyze the situation in which either the club or the national team chooses the duration $d$; second, we examine what happens when the club and the

\footnotetext{
${ }^{12}$ See also Proposition 2.
} 


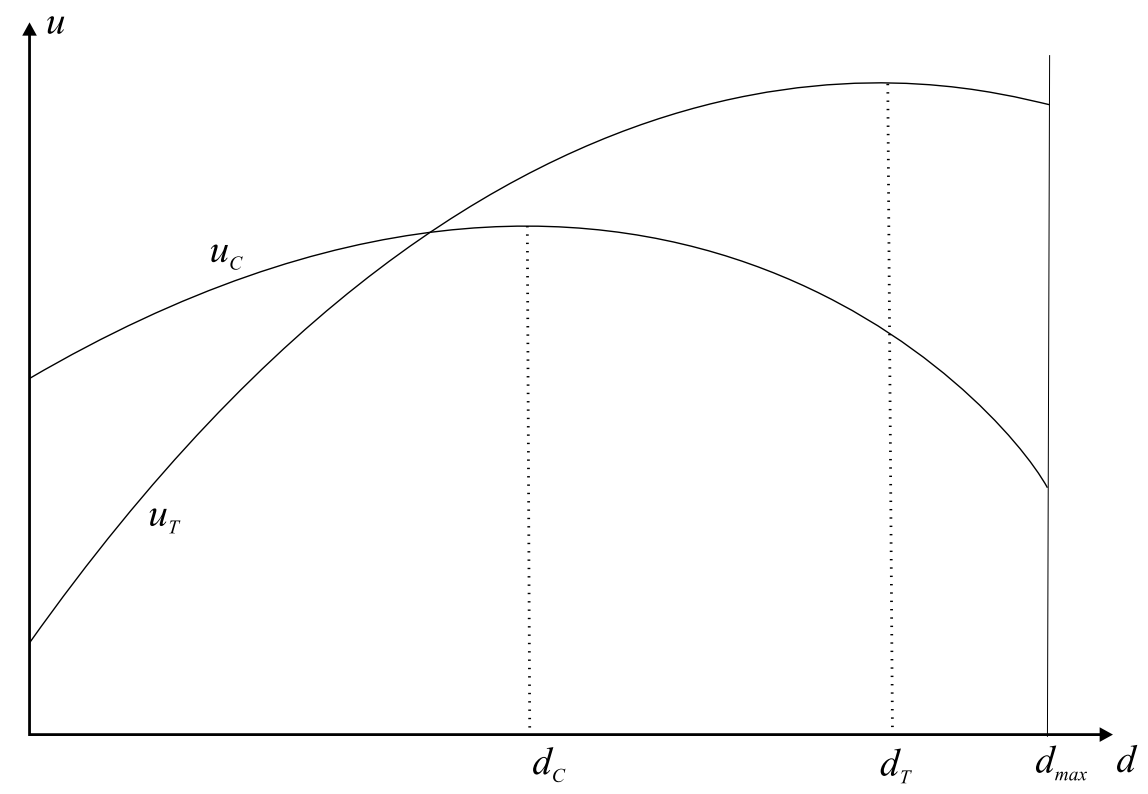

Figure 2: Utility of club and national team

national team bargain over duration $d$; third, we test how bargaining with upper limits to the feasible compensation might influence the situation; fourth, we derive the possible effects of an intervention by a governing body.

\subsection{The club or the national team chooses the duration $d$}

As a starting point, we assume that either $C$ or $T$ can choose $d$ but that no financial compensation is allowed to be paid by $T$ to $C$ for the release of players. ${ }^{13}$ Recall that $d_{C}\left(d_{T}\right)$ is the duration that the club (national team) would choose optimally. The following proposition indicates that neither $d_{C}$ nor $d_{T}$ is socially optimal.

Proposition 2 (i) If the club chooses the duration $d$, the players stay with the national team for an inefficiently short period of time, i.e., $d_{C}<d_{f b}$.

(ii) If the national team chooses the duration d, the players stay with the national team for an inefficiently long period of time, i.e., $d_{T}>d_{f b}$.

Proof. See Appendix A.2.

Compared with the socially optimal solution, $C$ would want to reduce $d$, whereas $T$ would want to increase $d$ because $u_{C}^{\prime}\left(d_{f b}\right)<0$ and $u_{T}^{\prime}\left(d_{f b}\right)>0$. The intuition

\footnotetext{
${ }^{13}$ Note that it is more realistic to assume that $C$ is allowed to choose $d$. After all, it is the club that employs (and pays) the players. Hence, the club should be able to order the players to stay with the national team or to come back to practice with and play for the club's team.
} 
behind part (i) of Proposition 2, i.e., the behavior of the club, is as follows. The club chooses $d$ in order to maximize its own utility $u_{C}(d)$. By focusing on its own utility, however, it neglects the externality that it imposes on the national team. Because the externality is neglected and the national team prefers a relatively higher value of $d$, the club decides to let its players go to the national team for an inefficiently short period of time. A similar intuition applies to part (ii) of the proposition.

Because of the inefficiency, one may look for ways to improve the situation. One obvious possibility is that the club and the national team negotiate over $d$, with the national team potentially offering the club a compensation $p$ if $d$ is increased above $d_{C}$. This possibility is analyzed in the next section.

\subsection{The club and the national team bargain over the dura- tion $d$}

In this subsection, we assume that $T$ can pay $C$ financial compensation for the release of players. We consider the following simple bargaining game. With probability $q \in(0,1), C$ makes a take-it-or-leave-it-offer to $T$ and with probability $1-q$, instead, $T$ makes a take-it-or-leave-it-offer to $C .{ }^{14}$ The offer consists of the duration $d$ of the players' stay at the national team and financial compensation $p>0$ paid by the national team to the club. The probability $q$ measures the parties' relative bargaining power: the larger (smaller) is $q$, the higher is the bargaining power of $C$ $(T)$.

First, we analyze the bargaining game under the assumption that $C$ proposes the offer (which happens with probability $q$ ). In this case, $C$ chooses the offer $(d, p)$ that solves the following constrained maximization problem:

$$
\max _{d \in D, p \in \mathbb{R}_{+}} u_{C}(d)+p \text { s.t. } u_{T}(d)-p \geq u_{T}\left(d_{C}\right)
$$

$C$ proposes an offer $(d, p)$ to maximize the sum of its utility $u_{C}(d)$ of sending players for duration $d$ to the national team and the compensation $p$ received from $T$ under the constraint that $T$ accepts the offer. Hence, $T$ 's pay-off from accepting

\footnotetext{
${ }^{14}$ Note that this kind of bargaining game is well accepted in the literature (see Hart, 1995; Schmitz, 2006 and Gürtler, 2011).
} 
$d$ and paying compensation $p$ must not fall short of its pay-off from declining the offer. We assume that if the offer is declined, the negotiations break down and $C$ chooses its utility-maximizing duration $d_{C}$. In the optimum, $(d, p)$ is chosen to make the constraint binding, i.e., $p=u_{T}(d)-u_{T}\left(d_{C}\right)$. Hence, the maximization problem simplifies to $\max _{d \in D} u_{C}(d)+u_{T}(d)-u_{T}\left(d_{C}\right)$ and we derive the solution as $d^{*}=d_{f b} \cdot{ }^{15}$ It follows that the socially optimal duration $d_{f b}$ is chosen and $C$ receives compensation of $p_{C}:=u_{T}\left(d_{f b}\right)-u_{T}\left(d_{C}\right)>0$.

In the next step, we assume that $T$ makes a take-it-or-leave-it-offer to $C$ (which happens with probability $1-q$ ). With a similar interpretation to the previous one, the optimal offer $(d, p)$ solves

$$
\max _{d \in D, p \in \mathbb{R}_{+}} u_{T}(d)-p \text { s.t. } u_{C}(d)+p \geq u_{C}\left(d_{C}\right)
$$

It should be noted that, now, $T$ maximizes the sum of its utility $u_{T}(d)$ minus the compensation $p$ it has to pay to $C$ under the constraint that $C$ accepts the offer. Hence, $C$ 's pay-off from accepting $d$ and receiving $p$ must not be lower than its pay-off from declining the offer. Again, we assume that if the offer is declined, $C$ chooses its utility-maximizing duration $d_{C} \cdot{ }^{16}$ In the optimum, $(p, d)$ is chosen such that the constraint in the optimization problem is binding, i.e., $p=u_{C}\left(d_{C}\right)-u_{C}(d)$. The maximization problem then becomes $\max _{d \in D} u_{T}(d)-u_{C}\left(d_{C}\right)+u_{C}(d)$ and the socially optimal duration $d_{f b}$ is implemented. ${ }^{17}$ As a result, $T$ offers $C$ compensation of $p_{T}:=u_{C}\left(d_{C}\right)-u_{C}\left(d_{f b}\right)>0$. The next proposition summarizes the results.

Proposition 3 (i) If the club and the national team are allowed to bargain over the duration $d$, then the socially optimal duration $d_{f b}$ is implemented regardless of which makes the offer.

(ii) The financial compensation paid by $T$ to $C$ is $p_{C}=u_{T}\left(d_{f b}\right)-u_{T}\left(d_{C}\right)$ with probability $q$ and $p_{T}=u_{C}\left(d_{C}\right)-u_{C}\left(d_{f b}\right)$ with probability $1-q$. The expected compensation $E[p]=q \cdot p_{C}+(1-q) \cdot p_{T}$ increases with $C$ 's bargaining power $q$ because $p_{C}>p_{T}$.

\footnotetext{
${ }^{15}$ Since $u_{T}\left(d_{C}\right)$ is a constant, it follows immediately that $C$ chooses $d^{*}=d_{f b}$ to maximize $u_{C}(d)+u_{T}(d)$.

${ }^{16}$ Note that this assumption guarantees non-negative compensation that is paid by $T$ to $C$. Even if this assumption is relaxed, i.e., in the case that $T$ chooses its utility-maximizing duration $d_{T}$ after the breakdown of the negotiations, the socially optimal duration would still be implemented.

${ }^{17}$ Note that $u_{C}\left(d_{C}\right)$ is a constant and therefore $u_{C}(d)+u_{T}(d)$ is maximized by choosing $d_{f b}$.
} 
(iii) The total utility of the club $U_{C}$ and the national team $U_{T}$ is given by

$$
\begin{aligned}
& U_{C}=q \cdot\left(u_{C}\left(d_{f b}\right)+p_{C}\right)+(1-q) \cdot u_{C}\left(d_{C}\right), \\
& U_{T}=q \cdot u_{T}\left(d_{C}\right)+(1-q) \cdot\left(u_{T}\left(d_{f b}\right)-p_{T}\right) .
\end{aligned}
$$

\section{Proof. See Appendix A.3.}

The main implication of Proposition 3 posits that the socially optimal solution is implemented once the club and the national team are allowed to negotiate over the duration of the players' stay with the national team. This result holds independent of whether $C$ or $T$ makes the offer. Even though the socially optimal duration is implemented in both scenarios, the two scenarios differ with respect to the financial compensation paid by $T$ to $C$. The size of this compensation depends on who is allowed to propose an offer and is either $p_{C}=u_{T}\left(d_{f b}\right)-u_{T}\left(d_{C}\right)$ or $p_{T}=u_{C}\left(d_{C}\right)-$ $u_{C}\left(d_{f b}\right)$. If $C$ makes the offer, the compensation it receives is higher than in the scenario in which $T$ makes the offer, i.e., $p_{C}>p_{T}$. Therefore, greater bargaining power of the club implies that higher compensation has to be paid by the national team. One can assume that larger clubs or more powerful club associations such as the German Football League (DFL) or the English Premier League (PL) have greater bargaining power vis-à-vis the national team and therefore will obtain higher financial compensation for their players. Figure 3 graphically illustrates the results from Proposition 3.

\subsection{Bargaining with upper limits to the feasible compensa- tion}

The results derived so far indicate that $C$ and $T$ might be able to solve their problems on their own and that intervention by a governing body (like an international sports association, such as FIFA in football) is not necessary. In practice, however, international sports associations often intervene and set clear rules for the length of time players have to stay with their national teams. A rationale for such interventions by a governing body can be given when frictions are introduced into the bargaining process, as bargaining then no longer leads to an efficient solution. Different frictions are imaginable, such as incomplete information and financial 


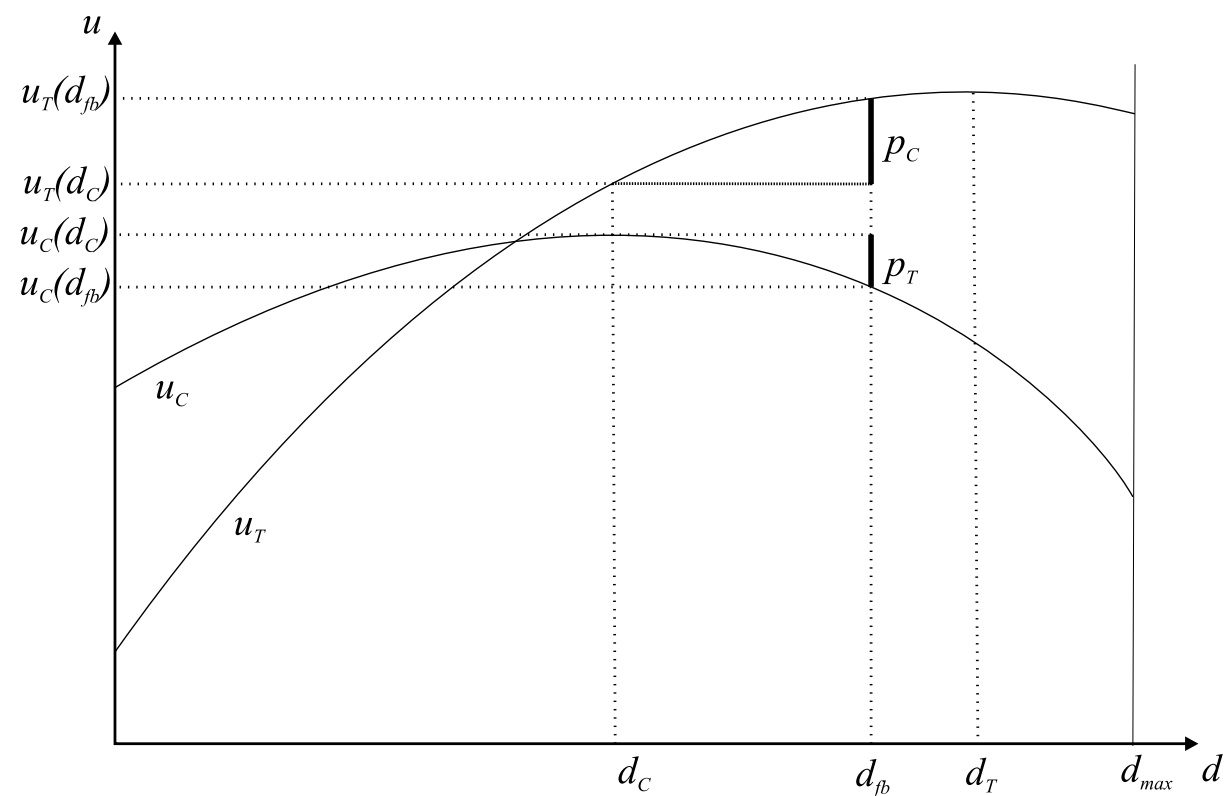

Figure 3: Socially optimal duration and financial compensation

constraints. To keep things simple, we follow the latter approach and assume the parties to be financially constrained so that there is an upper limit $\hat{p}$ to the feasible compensation paid by $T$ to $C .{ }^{18}$ Of course, this upper limit affects the behavior only if $\hat{p}<p_{C}$, so we suppose that this is the case. As just indicated, bargaining does not always lead to the socially optimal solution in this case.

Proposition 4 If there is an upper bound $\hat{p}<p_{C}$ to the feasible compensation paid by $T$ to $C$, then the two parties are not always able to achieve the socially optimal duration $d_{f b}$ via bargaining.

\section{Proof. See Appendix A.4.}

Proposition 4 shows that the socially optimal duration will no longer be achieved if restrictions are introduced regarding the feasible compensation. The intuition is as follows. When making an offer, a party wants to achieve two aims. It wants to increase the size of the "surplus" that can be distributed among the parties and it wants to secure a large share of this surplus. When there are no bounds to the feasible compensation, each party has two independent instruments available to achieve these two aims. A party chooses $d$ so as to maximize the size of the surplus (which leads to the socially optimal duration $d_{f b}$ ) and $p$ to increase its share in

\footnotetext{
${ }^{18}$ This assumption appears reasonable for national sports federations in poor countries which might not be able to pay the amount of money requested by some clubs.
} 
the surplus. When there is an upper bound to $p$, however, $p$ is only of limited use for distributing the surplus. Then $d$ is not only used to determine the size of the surplus, but also to distribute it among the parties. This dual role induces $d$ to move away from the socially optimal duration $d_{f b}$.

\subsection{Intervention of a governing body}

In this subsection, we show that a governing body, like an international sports association has an instrument with which it can install the socially optimal duration. ${ }^{19}$ Such an intervention of a governing body makes sense if the bargaining between the club and the national team is no longer expected to produce a socially optimal outcome. In the current model, there is an easy way for a sports association to reinstall the socially optimal duration. It can simply impose a lower bound $\hat{d}$ on the amount of time a player must spend with the national team. If this lower bound is set equal to $d_{f b}$, the club and the national team will agree on this level because they both prefer $d_{f b}$ to a duration $d$ above $d_{f b}$ if financial compensation is taken into account. This obvious result is formalized in the following corollary.

Corollary 2 If a sports association imposes a lower bound $\hat{d}=d_{f b}$ on the duration of the players' stay with the national team and the club has to obey this rule, then the outcome of the bargaining between $C$ and $T$ is the socially optimal duration $d_{f b}$.

Proof. Straightforward.

\section{Conclusion}

In this paper, we develop a theoretical bargaining model to analyze the conflict between a club and a national team regarding the release of players. We analyze whether interventions in this conflict by a governing body are necessary and socially desirable. In our model, we consider a representative club and a national team. Both agree that it is good for players to spend some time with the national team but disagree about the optimal duration of the players' stay with the national team.

\footnotetext{
${ }^{19}$ For example, in the case of soccer, FIFA sets rules concerning the minimal duration a player has to be released to the national team and is able to enforce this rule.
} 
We show that a socially optimal duration of the players' stay exists. However, if no financial compensation is allowed to be paid by the national team to the club, both parties will end up with a socially inefficient solution. In the case that the club chooses the duration, the players stay with the national team for an inefficiently short period of time, while the opposite is true if the national team chooses the duration. If, instead, the club and the national team are allowed to bargain over the duration and financial compensation paid by the national team to the clubs is possible, then the socially optimal duration is implemented regardless of which makes the offer. The size of this compensation depends on who is allowed to propose an offer and the expected compensation increases with the club's bargaining power. Under the assumption that the national team is financially constrained and is not able to pay the compensation demanded by the club, we find that the two parties are not able to achieve the socially optimal outcome through bargaining. Nevertheless, if a governing body imposes and enforces a lower bound on the duration of the players' stay then the bargaining between the club and the national team will yield the socially optimal outcome.

The qualitative findings from the model are robust to several model generalizations. As an example, we could extend the model to account explicitly for player quality. A higher player quality probably has an effect on the utilities of both the clubs and the national teams, thereby changing the exact values of the optimal durations of the players' stay with the national team and the financial compensation. The general finding that a governing body should intervene when the bargaining between the club and the national team is not without friction, however, continues to hold. The same is true when there is more than one club, as long as the clubs are homogeneous. When heterogeneity is introduced (e.g., players of differing quality or clubs with different utility functions), the intervention of a governing body sometimes improves social welfare. The efficient solution, however, may not be achievable anymore. To understand this, suppose that players are of differing quality. Then, the socially optimal duration of a player's stay with the national team depends on the player's quality. A single lower bound to this duration, which is equal for all kinds of players independent of their ability, no longer ensures the choice of the optimal duration for players of all quality levels. 
It is important to mention that the predictions of our model are transferable to other sports because the general conflict between clubs and national teams regarding the release of players occurs in many team sports. For example, the International Basketball Federation (FIBA) states:

It is within the spirit of all FIBA Regulations that players make themselves available for competitions of both their club and their national team. The national member federations are encouraged to enact regulations securing the participation of all players under their jurisdiction in their respective national teams (Internal Regulations 2010, Art. H.1.9).

Concerning the release of players to national teams, this statement is not very restrictive and suggests that FIBA has less enforcement power in this area than FIFA. Furthermore, with on average 82 matches played in a regular North America Basketball Association (NBA) season (and 16 to 28 additional games in the playoffs) as well as highly paid superstars, the cost of the secondment of talent time is higher for (NBA) basketball clubs than it is for football clubs. Altogether these might be possible reasons why superstars like Dirk Nowitzki (Germany), Kobe Bryant (USA), Pau Gasol (Spain) and Tony Parker (France) did not appear in the World Cup in 2010 in Turkey. While these arguments imply that there are certain sports in which the national team activities are of minor importance to the respective club markets, ${ }^{20}$ other sports exist, like rugby, in which national teams such as the All Blacks (New Zealand) and the Springbocks (South Africa) have a huge impact on the club markets. It is probable that the willingness to release players to the national team is therefore higher in these sports.

\footnotetext{
${ }^{20}$ Recent events from the National Hockey League (NHL) underscore this statement. While most of the players from the NHL want to take part in the Olympic Winter Games in 2014, the club owners currently do not intend to release their players (New York Times, 2009).
} 


\section{A Appendix}

\section{A.1 Proof of Proposition 1}

Because $D$ is a compact interval and $U(d)=u_{C}(d)+u_{T}(d)$ is a continuous function on $D$, according to the Weierstrass theorem, a maximum $d_{f b}$ of total utility $U(d)$ exists. Uniqueness of the solution is guaranteed because $U(d)$ is a strictly concave function and $D$ is a convex set, where $d_{f b} \equiv \arg \max _{d \in D} U(d)$.

\section{A.2 Proof of Proposition 2}

Part (i). The club chooses $d$ in order to maximize $u_{C}(d)$. Again, a solution to the maximization problem exists, is unique and characterized by the first-order condition $u_{C}^{\prime}\left(d_{C}\right)=0$. If $u_{C}^{\prime}\left(d_{C}\right)=0$, A1 implies that $u_{T}^{\prime}\left(d_{C}\right)>0$. Accordingly, we have $u_{C}^{\prime}\left(d_{C}\right)+u_{T}^{\prime}\left(d_{C}\right)>0$. Since $u_{C}(d)+u_{T}(d)$ is strictly concave, we immediately obtain $d_{C}<d_{f b}$.

Part (ii). This part can be shown analogously to part (i).

\section{A.3 Proof of Proposition 3}

Part (i) and (iii). These parts follow directly from the above calculations.

Part (ii). We derive

$$
\frac{\partial E[p]}{\partial q}=p_{C}-p_{T}=u_{T}\left(d_{f b}\right)+u_{C}\left(d_{f b}\right)-\left(u_{T}\left(d_{C}\right)+u_{C}\left(d_{C}\right)\right)>0
$$

because $d_{f b}$ is the unique maximizer of $u_{T}(d)+u_{C}(d)$.

\section{A.4 Proof of Proposition 4}

Suppose $C$ is allowed to make a take-it-or-leave-it-offer to $T$. The maximization problem is

$$
\max _{d \in D, p \in[0, \hat{p}]} u_{C}(d)+p \text { s.t. } u_{T}(d)-p \geq u_{T}\left(d_{C}\right) .
$$

By way of contradiction suppose that $C$ proposes $d_{f b}$. Since $\hat{p}<p_{C}=u_{T}\left(d_{f b}\right)-$ $u_{T}\left(d_{C}\right), C$ cannot choose $p$ so high that $u_{T}\left(d_{f b}\right)-p \geq u_{T}\left(d_{C}\right)$ binds. Instead, $C$ chooses $p=\hat{p}$ and receives $u_{C}\left(d_{f b}\right)+\hat{p}$. Since the constraint $u_{T}(d)-p \geq$ 
$u_{T}\left(d_{C}\right)$ is slack at the solution $d=d_{f b}$ and $p=\hat{p}, C$ could marginally decrease $d$ below $d_{f b}$ without violating any of the constraints. This would increase $C$ 's pay-off, contradicting the optimality of $d_{f b}$. 


\section{References}

Baumeister, T. M., Becher, C. \& Eschweiler, M. (2004), Abstellung von Spielern für Auswahlmannschaften - Zehn Thesen zu den ökonomischen Chancen und Risiken aus Vereinssicht, in M. Bieling, M. Eschweiler \& J. Hardenacke, eds, 'Businessto-Business-Marketing im Profifussball', DUV, Wiesbaden, pp. 305-320.

Benz, M. \& Franck, E. (2005), 'Do soccer teams have to be compensated for releasing star players to the national teams?', ISU Working Paper Series No. 34.

DFB (2011), 'Grundlagenvertrag', (Access on 14th November 2011 http://www.dfb.de/uploads/media/Grundlagenvertrag.pdf).

Dietl, H., Franck, E., Lang, M. \& Rathke, A. (2011), 'Salary Cap Regulation in Professional Team Sports', Contemporary Economic Policy (forthcoming).

Dietl, H., Lang, M. \& Rathke, A. (2009), 'The Effect of Salary Caps in Professional Team Sports on Social Welfare', B.E. Journal of Economic Analysis and Policy 9, Article 17.

Dietl, H., Lang, M. \& Rathke, A. (2011), 'The Combined Effect of Salary Restrictions and Revenue Sharing in Sports Leagues', Economic Inquiry 49(2), 447-463.

Dietl, H., Lang, M. \& Werner, S. (2009), 'Social Welfare in Sports Leagues with Profit-Maximizing and/or Win-Maximizing Clubs', Southern Economic Journal 76(2), 375-396.

Ekstrand, J., Waldén, M. \& Hägglund, M. (2004), 'A congested football calendar and the wellbeing of players: correlation between match exposure of European footballers before the World Cup 2002 and their injuries and performances during that World Cup', British Journal of Sports Medicine 38(4), 493.

Fort, R. \& Lee, Y. (2007), 'Structural Change, Competitive Balance, and the Rest of the Major Leagues', Economic Inquiry 45(3), 519-532.

Fort, R. \& Quirk, J. (1995), 'Cross-Subsidization, Incentives, and Outcomes in Professional Team Sports Leagues', Journal of Economic Literature 33, 12651299. 
Fort, R. \& Quirk, J. (2011), 'Optimal Competitive Balance in a Season Ticket League', Economic Inquiry 49, 464473.

Gartenschläger, L. (2010), 'Wir brauchen das Geld aus Länderspielen. Interview mit Oliver Bierhoff', Die Welt (13.10.2010).

Gürtler, O. (2007), 'A rationale for the coexistence of central and decentral marketing in team sports', German Economic Review 8(1), 89-106.

Gürtler, O. (2011), 'A Strategic Rationale for the Use of Sell-On Fees in European Sports', Journal of Sports Economics (forthcoming).

Hägglund, M., Waldén, M. \& Ekstrand, J. (2009), 'UEFA injury study- an injury audit of European Championships 2006 to 2008', British Journal of Sports Medicine 43(7), 483-489.

Hart, O. (1995), Firms, contracts, and financial structure, Oxford University Press, USA.

Hübl, L. \& Swieter, D. (2002), 'Der Spielemarkt in der Fussball Bundesliga', Zeitschrift für Betriebswirtschaft 72, 105-123.

Késenne, S. (2000), 'The Impact of Salary Caps in Professional Team Sports', Scottish Journal of Political Economy 47, 422-430.

Késenne, S. (2003), 'The salary cap proposal of the G-14 in European football', European Sport Management Quarterly 3, 120-128.

Késenne, S. (2007), The Economic Theory of Professional Team Sports - An Analytical Treatment, Edward Elgar, Cheltenham, UK.

Klein, J. (2009), 'Ovechkin not wavering on support of Olympics', New York Times (08.10.2009).

Kräkel, M. (2007), 'A note on revenue sharing in sports leagues', Journal of Sports Economics 8(3), 309-316.

Lucifora, C. \& Simmons, R. (2003), 'Superstar effects in sport', Journal of Sports Economics 4(1), 35-55. 
Pawlowski, T. \& Anders, C. (2011), 'Stadium attendance in German professional football The (un)importance of uncertainty of outcome reconsidered', Applied Economics Letters (forthcoming).

Pawlowski, T., Breuer, C. \& Hovemann, A. (2010), 'Top Clubs Performance and the Competitive Situation in European Domestic Football Competitions', Journal of Sports Economics 11(2), 186-202.

Schmidt, J. (2010), 'Wie man Kommerz sinnvoll nutzt', Kölnische Rundschau (29.04.2010).

Schmitz, P. W. (2006), 'Information gathering, transaction costs, and the property rights approach', American Economic Review 96(1), 422-434.

Sport.t-online (2008), 'Abstellen von Nationalspielern lohnt sich wieder', (Access on 1st June 2010 at http://sport.t-online.de/fussball-bundesliga-abstellen-vonnationalspielern-lohnt-sich-wieder).

Szymanski, S. (2001), 'Income inequality, competitive balance and the attractiveness of team sports: Some evidence and a natural experiment from English soccer', The Economic Journal 111(469), 69-84.

Szymanski, S. (2003), 'The Economic Design of Sporting Contests', Journal of Economic Literature 41, 1137-1187.

Szymanski, S. \& Késenne, S. (2004), 'Competitive Balance and Gate Revenue Sharing in Team Sports', Journal of Industrial Economics 52, 165-177.

Tripcke, G. (2001), Rechtliche und wirtschaftliche Fragen und Probleme im Verhältnis zwischen Verband und Liga im Hinblick auf Nationalmannschaften, in M. Büch, ed., "Verschwinden nationale Auswahlmannschaften in einer "offenen" Gesellschaft?', Sportverlag Strauss, Köln.

UEFA (2008), 'Financial report 2007/08', Nyon: Switzerland .

Vrooman, J. (2007), 'Theory of the Beautiful Game: The Unification of European Football', Scottish Journal of Political Economy 54, 314-354. 
Vrooman, J. (2008), 'Theory of the Perfect Game: Competitive Balance in Monopoly Sports Leagues', Review of Industrial Organization 31, 1-30.

Waldén, M., Hägglund, M. \& Ekstrand, J. (2007), 'Football injuries during European Championships 2004-2005', Knee Surgery, Sports Traumatology, Arthroscopy 15(9), 1155-1162. 